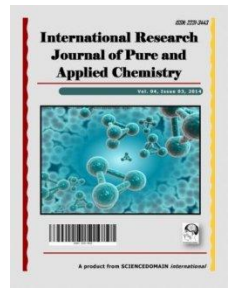

International Research Journal of Pure \&

Applied Chemistry

12(3): 1-20, 2016, Article no.IRJPAC. 27469

ISSN: 2231-3443, NLM ID: 101647669

SCIENCEDOMAIN international

www.sciencedomain.org

\title{
Chronological Review of the Catalytic Progress of Polylactic Acid Formation through Ring Opening Polymerization
}

\author{
Satya P. Dubey ${ }^{1 *}$, Hrushikesh A. Abhyankar ${ }^{1}$, Veronica Marchante ${ }^{1}$, \\ James L. Brighton ${ }^{1}$ and Kim Blackburn ${ }^{1}$ \\ ${ }^{1}$ Advanced Vehicle Engineering Centre, School of Aerospace, Transport and Manufacturing, \\ Cranfield University, Cranfield, MK43 OAL, United Kingdom.
}

\begin{abstract}
Authors' contributions
The reported research work was a multi-disciplinary, collaborative effort. Author SPD is the lead researcher and author of this manuscript. A detailed literature review and information regarding the ROP of lactide in the literature was conducted by author SPD as part of his doctoral thesis. Authors $S P D, V M, H A A, J L B$ and $K B$ contributed to the development of detailed study for the state-of-the art in the field of chronological development in the field of PLA processing. The author's contributed equally for making the manuscript more scientific and meaningful in terms of English language.

Article Information

DOI: $10.9734 /$ RJPAC/2016/27469

Editor(s):

(1) Rakeshwar Bandichhor, API- R\&D, Innovation Plaza, Dr. Reddy's Laboratories Hyderabad, India. (2) Wenzhong Shen, State Key Laboratory of Coal Conversion, Institute of Coal Chemistry, CAS, China (3) Sung Cheal Moon, Korea Institute of Materials Science (KIMS), Industrial Technology Support Division, Changwon, Republic of Korea.

(1) Bibiao Jiang, Changzhou University, China. (2) Ganesh S. Bhusari, Tulsiamji Gaikwad-Patil College of Engineeing and Technology, Nagpur, India. (3) Jesús Miguel Contreras Ramírez, Universidad de Los Andes, Venezuela. (4) Anonymous, Medical University of Warsaw, Poland. Complete Peer review History: http://www.sciencedomain.org/review-history/15723
\end{abstract}

Review Article

Received $2^{\text {nd }}$ June 2016

Accepted $27^{\text {th }}$ July 2016

Published 9 $^{\text {th }}$ August 2016

\section{ABSTRACT}

The disposal of a large amount of polymer waste is one of the major challenges of this century. Use of bio-degradable polymers obtained from sustainable sources presents a solution to this problem. Poly lactic acid (PLA), a bio-degradable polymer, can be synthesized from sustainable sources as corn, starch, sugarcane and chips. Ring opening polymerization (ROP) of Lactide (LA) monomer using metal/bimetallic catalyst ( $\mathrm{Sn}, \mathrm{Zn}$ or $\mathrm{Al}$ ) is the preferred method for synthesis of PLA. However, the PLA synthesized using such catalysts may contain trace elements of the catalyst. 
These catalyst traces are known carcinogens and as such should be (ideally) eliminated from the process. Use of the organic catalyst instead of metallic catalysts, may be one of the prominent solutions.

Organic catalysts require the higher energy of activation for the ROP reaction of LA. Such energy requirement can be achieved through the application of alternative energy during the reaction. Alternative energy sources such as LASER, Ultrasound and microwave are prominent options to implement and process the ROP of PLA. This paper is an effort to emphasize the chronological review and to establish the current state-of-the-art in the field of PLA research.

Keywords: Polymer; poly-lactic acid (PLA); ring opening polymerization (ROP); metal-catalyst; bio-degradable; alternative energy $(A E)$.

\section{ABBREVIATIONS}

PLA: Poly(lactic acid); PLLA: Poly Levo Lactic Acid; LA: Lactide; L-LA: Levo Lactic Acid; DL-LA: Dextro, Levo Lactic Acid; CA: Cellulose acetate; PA: Polyamide; PBS: Poly-butylene succinate; PP: Poly-propylene; PU: Poly-urethane; PET: Polyethylene terephthalate; HIPP: High impact polystyrene; PVC: Poly vinyl chloride; ROP: Ring opening polymerization; UFDA: U.S. Food and Drug Administration; AE: alternative energy; OMt-K10: Montmorilloniate-K10; DMAP: Di-alkylamino-pyridine; PPY: Polypyrrole; NHC: N-heterocyclic carbine; bvp4c: Boundary Value Problems; MINDO: Modified Intermediate Neglect of Differential Overlap; MO: Molecular orbital; B3LYP: Becke 3-Parameter (Exchange); Lee: Yang and Parr (correlation; density functional theory); UV: Ultra Violet; PCL: poly (E-caprolactone); Rex: Reactive extrusion; LRP: living free radical polymerization.

\section{INTRODUCTION}

The disposal of a large amount of polymer waste mainly the daily use consumer product is one of the major challenges of this century. Use of biodegradable polymers obtained from sustainable sources emerges as a promising solution to environmental waste. However, substituting traditional polymers derived from petroleum products with a bio-degradable polymer is not sufficient to overcome all the disadvantages of using petroleum based polymers. Large scale industrial production of biopolymers can introduce impurities into the finished product that can be toxic to the end user and harmful to the environment. For example, use of metallic or bimetallic catalysts for the synthesis of biopolymers may lead to industrial scale throughput, but it also creates some serious health issues like carcinogenic effect [1-9]. Hence, research efforts need to be directed to eliminate the use of such catalysts from the production process.

Ring opening polymerization (ROP) of LA monomer is one of the most preferred methods for synthesis of Poly(lactic acid) PLA. The state of the art techniques developed by Dubois et al., Witzke et al. and Yu et al. [8-11] for the ROP of LA is based on the metallic and bimetallic catalyst ( $\mathrm{Sn}, \mathrm{Zn}$, and $\mathrm{Al})$ in suitable solvents. This process leads to throughputs in the range of 30 -
$40 \mathrm{~kg} / \mathrm{hr}$, making production scalable and cost effective. However, as the metallic and bimetallic catalysts were established to be carcinogenic, there is an urgent need to explore suitable alternatives.

The metallic catalysts aluminium isopropoxide $\mathrm{Al}(\mathrm{OPr})_{3}$ zinc lactate $\left(\underline{\mathrm{C}}_{6} \underline{\mathrm{H}_{10}} \underline{\mathrm{O}_{6}} \underline{\mathrm{Zn}}\right)$ and stannous octoate $\left(\mathrm{Sn}(\mathrm{Oct})_{2}\right)$ etc. typically used in the production of PLA result in the production of a nucleophile or electrophile, which initiates the polymerization process. Replacing the metallic catalysts with non-metallic catalysts or some other metal-free source makes the production 'inefficient' because of low activation capacity of non-metallic catalysts. As a result, the throughput obtained from such a process is well below the requirements for industrial scale production (30$40 \mathrm{~kg} / \mathrm{hr}$ ). Kamber et al. [5] Wang et al. [6] and Basaran et al. [7] etc. reported the use of organic/metal-free catalysts in the production of biopolymers. These studies conclude that although the ROP of LA is possible, the production rate was much less (2-3 kg/hr) compared to metallic one $(20-40 \mathrm{~kg} / \mathrm{hr})$ for consumer product standard.

\section{ROP OF MONOMERS THROUGH METAL/ORGANIC CATALYST}

The basis of the ROP is opening the cyclic ring of monomers such as cyclic ether, amides 
(lactams) and esters (lactones). Then the opened ring acts as an active centre where other monomers join to form a larger polymer chain through ionic propagation. ROP consists of a sequence of initiation, propagation and termination reactions [12]. Once the process is started by the initiator, monomers add to the active polymer chain and increasing the chain length. A wide variety of cyclic monomers has been successfully polymerized by using ROP such as cyclic olefin, amines, sulphides etc. The suitability of polymerization of cyclic monomer depends on both thermodynamic and reaction kinetic factors [12].

\section{THERMO-DYNAMIC CONDITIONS FOR ROP OF CYCLIC MONOMERS}

The thermodynamic factors such as binding energy, entropy, and enthalpy of bond breaking and formation process play a very significant role in determining the relative stability of cyclic monomer and linear polymer structures during the conversion of cycloalkanes to the corresponding linear polymer [13]. ROP is thermodynamically favourable to all except the 6membered ring. The order of thermodynamically favoured cyclic structure is $3>4>8>5>7$ atoms. The trend is a result of bond angle strain in 3 and 4-membered rings, eclipsed conformational strain in the 5-membered ring and trans-annular strain in 7 and 8-membered ring [12]. Thermodynamic parameters alone do not guarantee the polymerization of the cyclic monomer as shown in the case of the 6membered ring. Polymerization also requires a favourable kinetic pathway to open the ring and undergo reaction. For nucleophilic or electrophilic attack by an initiator, existence of a heteroatom in the ring provides a suitable site resulting in further propagation by opening the ring. Such monomers polymerise when both thermodynamic and kinetic factors are favourable for the reaction [12].

\section{ROP OF LACTIDE AND POLY- CONDENSATION OF LACTIC ACID FOR PLA SYNTHESIS}

Based on the production rate and molecular weight, the two most efficient and common methods to produce PLA are polycondensation of lactic acid and ring opening polymerization of LA (Fig. 1). Poly-condensation involves removal of water of condensation by the use of solvent under high vacuum and high temperature. In general, it is the least expensive route, but in a solvent-free system, it is difficult to achieve high production rates $(30-40 \mathrm{~kg} / \mathrm{hr})$. To manufacture a low to intermediate molecular weight polymer, the poly-condensation approach was used by Carothers and is still used by Mitsui Toatsu Chemicals Inc. [14,15].

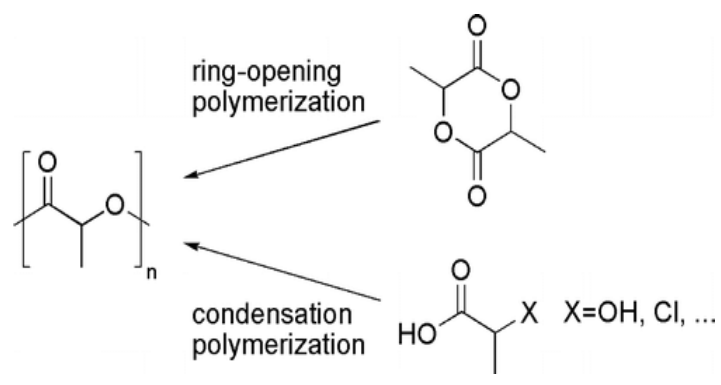

Fig. 1. Lactide and lactic acid monomer to form PLA polymer

The other efficient way to obtain PLA is the ROP of LA with suitable metal catalysts (tin, zinc, aluminium) in a suitable solvent [36]. Normally, the entropically favoured LA monomers are produced at the temperature below $180-200^{\circ} \mathrm{C}$ [19]. Based on cost and reaction time, ROP is preferred process for large-scale industrial production. Catalysts like $\mathrm{Al}(\mathrm{iOP})_{3}, \underline{\mathrm{C}}_{6} \underline{\mathrm{H}}_{10} \underline{\mathrm{O}}_{6} \underline{\mathrm{Zn}}$ and $\mathrm{Sn}(\mathrm{Oct})_{2}$ have been studied to enhance the ROP reaction productivity [36]. To get the higher molecular weight, use of other coupling agents or esterification-promoting agents are required, which increase cost and complexity [36,37]. However, obtaining high molecular weight polyesters with good mechanical properties is not easy. Among them, stannous octoate $\left(\mathrm{Sn}(\mathrm{Oct})_{2}\right)$, approved by the U.S. Food and Drug Administration (UFDA), is the most widely used due to high LA polymerization feature [38].

\subsection{ROP Mechanism of Lactide}

ROP is generally initiated by the attack of ionic (anionic or cationic) initiator on the cyclic ring monomer to create an active site for further addition of monomer(s) [16-18,21,22]. Reaction involves the nucleophilic attack of monomer on the oxonium ion Fig. 2.

In the case of active species determination, Kricheldorf et al. [36] reported that tin halogenides were actually converted into tin alkoxide and behave as real active species. Several ring-opening polymerizations proceed as living polymerizations and polymer molecular 
weight increases linearly with conversion and ratio of monomer to initiator [6]. ROP is the preferred way of polymerization because it results in polymers with high polymer molecular weight $[7,20,24,29]$.

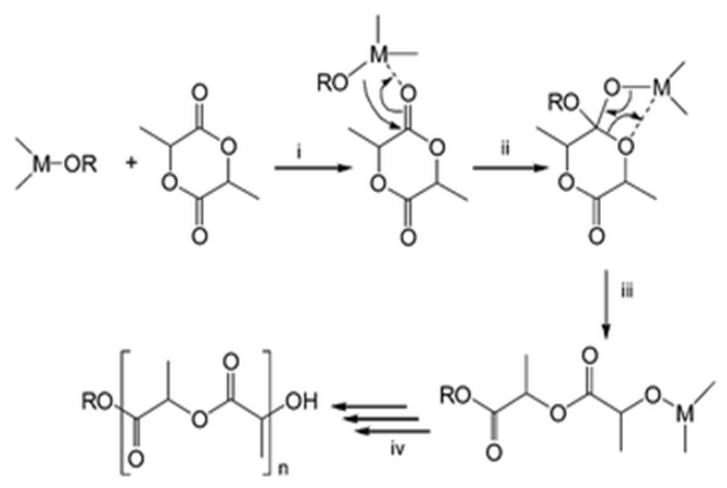

Fig. 2. Mechanism of ROP of lactide

\section{CHRONOLOGICAL SCIENTIFIC RESEARCH DEVELOPMENT IN PLA SYNTHESIS FIELD}

PLA as biocompatible and biodegradable class of polymer has garnered a lot of attention in past decades and has also resulted in industrial scale production at manufacturing units such as Nature work (USA) [33,39], Purac (Netherlands) [40], etc. In fact, the metal catalyst (in a suitable solvent) has been used for the synthesis of PLA for decades. Dubois et al. [41] in 1991 reported the mechanism of ROP of LA using Batch process and aluminium isopropoxide as a catalyst in toluene solvent. Witzke et al. [42] also reported reversible kinetics of L-LA in the ovendried container using stannous octoate as a catalyst in toluene solvent, incidentally leading to an adverse effect (toxicity, irritation) on human health. Jennifer et al. [43] reported that $\mathrm{Sn}(\mathrm{Oct})_{2}$ used in the polymerisation of LA is an irritant to the eyes, respiratory system, and skin. The different reaction stages involved in the polymerization of LA lead to the formation of impurities and side products. The use of $\mathrm{Sn}(\mathrm{Oct})_{2}$ or another metal catalyst is also very toxic and hazardous for environment although lactic acid and LA are non-toxic in nature [8].

Apart from the catalyst, the reaction time is also an important factor which decides the production cost and quality of commercial PLA. The reported reaction completion time for ROP kinetics by Dubois et al. [8] and others was several hours (50-100). Mehta et al. [44] reported the variation of the number average molecular weight of PLA with the time scale of 0-150 hours by using the experimental data from Dubois et al. Batch process [41]. Jacobsen et al. [2] and Banu et al. [9] using reactive extrusion for the polymerization of LA proposed the detailed study of ROP process. They observed that in initial few minutes the conversion rate reaches almost $95 \%$, but if the process lasts longer, side reactions (like intermolecular trans-esterification and scission) can decrease the polymer molecular weight. For the estimation of monomer conversion and average molecular weight along the extruder, Banu et al. [9] reported the material flow and mixing by using the Ludovic $\circledast$ commercial simulator.

As mentioned earlier, the drawbacks of metalcatalyst have resulted in the growth of organocatalysis as a prominent solution for ROP reactions. Basaran et al. [5] reported experimental technique detailing the synthesis and characterization of polylactide via the metalfree process. Consideration of Montmorilloniate$\mathrm{K} 10$ (OMt-K10) as organic filler and acid catalyst for polymerization of LA opens a suitable source of catalyst application to overcome impurity caused by metallic catalysts [5]. The work proposed the use of OMt-K10 filler both as the catalyst and inorganic filler to prepare the biopolymer nano-composite of PLA. OMt-K10 has a catalytic proton, which can act as an acid catalyst for the polymerization process of LA. As mentioned earlier by several research groups an increase in temperature during the polymerization process, initiates several side reactions which decrease the molecular weight of the resulting polymer $[37,43,45]$. Basaran et al. [5] also verified the effect of temperature and found that beyond $180^{\circ} \mathrm{C}$ the reaction behaviour started changing and beyond a certain temperature range $\left(180-200^{\circ} \mathrm{C}\right)$ the molecular weight started decreasing. Higher temperature like $185-190^{\circ} \mathrm{C}$ boosts unzipping and chain scission reactions and leads to the decrease of molecular weight as well as thermal degradation $[47,48]$. However, the basic principle of ROP process is still the backbone for all kind of new development and innovation in this field.

In the last few years, several research communities and groups have investigated the possibility to develop a technique through which the polymerization of LA becomes possible by using the metal- free or organic catalyst. Use of alternative energies such as microwave, LASER, and ultrasound source to achieve a precisely- 
controlled and efficient continuous polymerisation of high molecular weight PLA in a twin screw extruder is currently being investigated. To implement the effect of the metal-free catalyst in the reaction mechanism, a proper understanding of reaction kinetics is needed. It is necessary to develop a theoretical mathematical model to check the suitability of parameters (time, concentration, temperature and rate constants) in reaction mechanism for LA polymerization.

\section{REACTION MECHANISMS FOR PLA FORMATION USING ORGANIC CATALYSTS}

To replace the effect of the metallic catalyst as a catalyst for ROP of LA and its adverse effects on the environment, in 2007 Kamber et al. [6] proposed very detailed review on the state of the art of effectiveness of organic catalyst related ROP reactions mechanism and the importance of the organo-catalytic ring-opening polymerization. The work examined several methods for initiate the ROP such as cationic, anionic, enzymatic and other organic ROP. The initial reaction scheme to understand the reaction for ROP of LA is mentioned in Fig. 3.<smiles>C[C@@H]1OC(=O)[C@H](C)OC1=O</smiles>

L-lactide (L-LD)

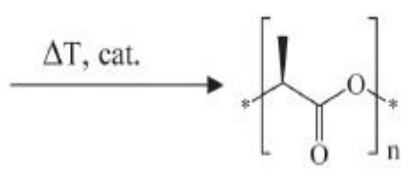

poly(L-lactide) (L-PLA)
Fig. 3. PLA formation routes

The reaction scheme referred to in Fig.3. describes the reaction procedure well but does not give all the details by highlighting the intermediate steps which control and are ultimately responsible for the molecular weight distribution and the molecular weight of the macromolecules. Once the polymerization reaction starts, it goes on to a final stage with certain molecular weight. As a result, step growth or chain growth processes influence the reaction. The step growth process explains the details of ROP process by providing effective details of intermediate reactions and helps to control the molecular weight of process with the emergence of "living" polymerization or active site reactions $[31,39,40,47]$.

Fig. 4 explains the details of several mechanisms such as coordination-insertion mechanism, activated monomer mechanism and monomeractivated mechanism versus chain end-activated mechanism.

(a)

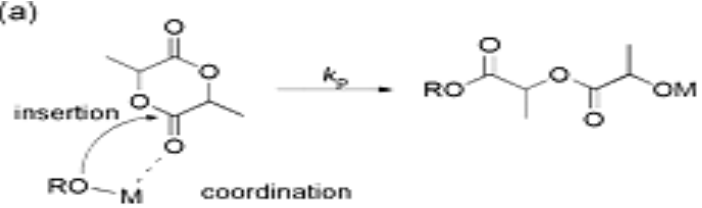

M: metal catalyst

(b)

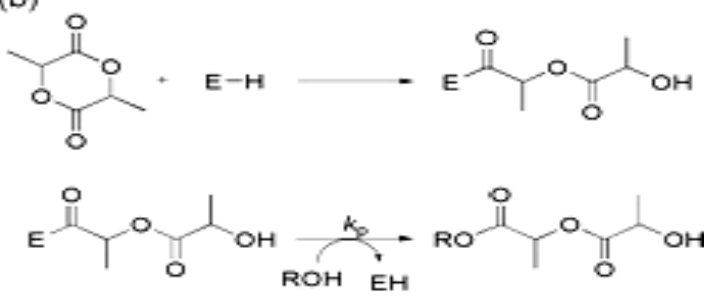

E: enzymatic catalyst

(c)

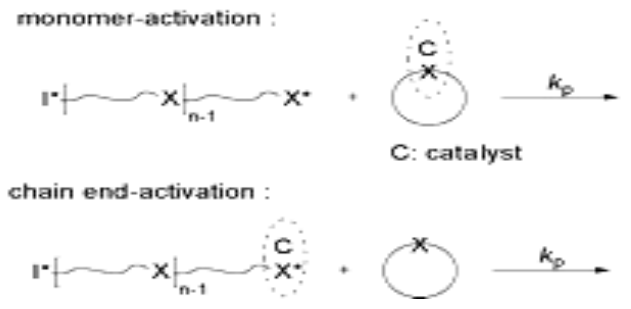

Fig. 4. Different mechanism for ROP process

In general, the ROP of lactides follows the coordination-insertion mechanism [48]. This is different from usual cationic and anionic mechanism in which free ions or ion pairs are the charged propagating species and their counterion share a covalent bond [80]. The coordinationinsertion mechanism is based on the coordination of the metal catalyst group with monomer ring and further attack of an alcohol group on the week site of monomer ring (Fig. 5). This mechanism shows better production yield and faster reaction times (20-60) $\mathrm{min}$ in ROP process [49]. There is also an alternative classification for enzymatic ROP known as an activated-monomer mechanism. In this process, the enzymes react with monomer and activate the monomer to enhance the polymer chain addition process [40]. The field of enzymecatalysed ROP was demonstrated in the application of a lipase (a type of an enzyme 
catalyst) for ROP of lactones by independent groups of Parmar et al. [35] Kobayashi et al. [40,] and Knani [34]. Enzymes show an effective stereo-active reaction and were extracted from renewable resources that can be easily recycled [9]. To define the role of a catalyst, classification of the catalytic process of ROP reactions either by chain end-activation or monomer-activation mechanism is crucial.

Several other ligands in organic and non-metallic catalysts are also capable of starting ROP of $L$ (LA), such as pyridine, phosphine and carbines. The first organo-catalyst used in living ROP of Lactide (LA) was reported in 2001, using basic amines such as di-alkyl-amino-pyridine (DMAP) and poly-pyrrole (PPY) as trans-esterification catalysts [50]. DMAP was used successfully not only for trans-esterification but also for many other organic transformations such as alkylation, acylation, nucleophilic substitutions, etc [52]. Because of these properties, DMAP has been the centre of several reviews $[51,53,54]$. The Fig. 5 describes the mechanism for ROP of LA using a pyridine such as DMAP.
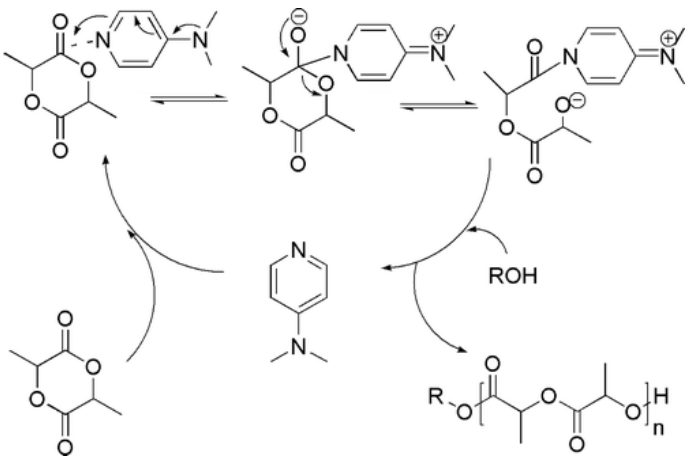

Fig. 5. DMAP acylation mechanism

In this series, phosphines are commonly known ligands in organometallic chemistry and homogenous catalysis. Phosphines are capable of mediating a wide variety of organic transformations including acylation reactions [52]. Several tertiary phosphines were used for trans-esterification catalysts of the ROP of Lactide (LA) [49]. In the presence of alcohol especially benzyl alcohol, phosphines were found to be an effective catalyst for ROP process of LA [38]. The phosphine catalysed polymerization process in dichloromethane $\left(\mathrm{CH}_{2} \mathrm{Cl}_{2}\right)$ or toluene was slower and required high temperature $(90-100)^{\circ} \mathrm{C}$ in comparison to those catalysed by DMAP [55]. The activity of several phosphine ligand catalysts for (LA) polymerization in decreasing order is as follows: tributylphosphine $\left(\mathrm{P}(\mathrm{n}-\mathrm{Bu})_{3}\right)>$ tertButylohosphine $\quad\left((\text { tert-Bu })_{3}\right) \quad>$ dimethylphenylphosphine $\quad\left(\mathrm{PhPMe}_{2}\right)$ $>$ methyldiphenylphosphine $\left(\mathrm{Ph}_{2} \mathrm{PMe}\right)>$ triphenylphosphine $\left(\mathrm{PPh}_{3}\right)>$ trimethoxyphosphine $\mathrm{P}(\mathrm{MeO})_{3}$. For nucleophilicmechanism the suitability is based on more basic and nucleophilic-alkyl-substituted phosphines for the effective LA polymerization catalysts $[44,56]$. The mechanism is shown in Fig. 6.

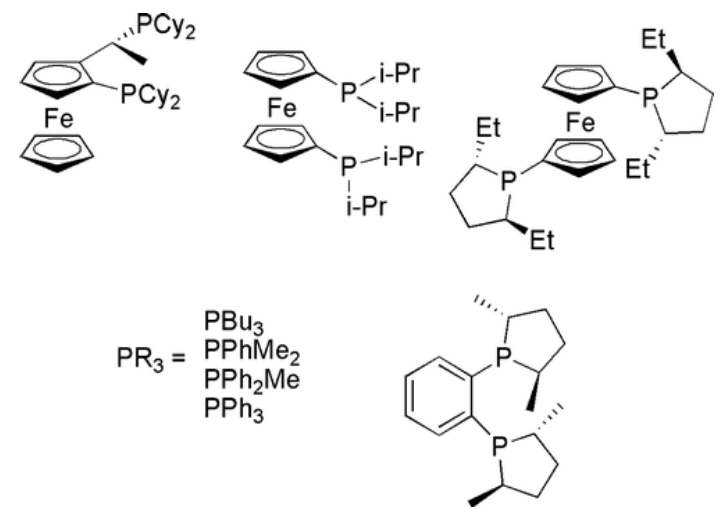

Fig. 6. Phosphine catalysis mechanism

Breslow introduced carbenes as a catalyst for polymerization, his studies steered researchers towards investigating the use of stabilized carbenes as the nucleophilic catalyst [57-59].

In the case of ROP, the use of different types of carbenes (unsaturated and saturated imidazolylidene and triazolylidene as the effective catalyst, have been investigated [60], [62]. The ROP depends on the nature of carbene and monomer. The reported rate of reaction was similar to one of the most active metal catalysts results from ROP of LA [52,61-63]. NHCs have higher nucleophilicity and basicity as compared to DMAP, which is responsible for the higher reaction rates. In the mechanism of polymerization of the lactones using carbene as the catalyst, the termination can be started by deactivation of the carbene introducing acetic acid, $\mathrm{CO}_{2}$ or $\mathrm{CS}_{2}$ which later forms the zwitterionic species i.e. a molecule with a positive and a negative charge and can be removed from the polymer by the precipitation process. In the nucleophilic mechanism, production of a zwitterionic intermediate is the key feature [64]. Nucleophilic attack of the carbene on the lactones creates zwitterionic species, followed by ROP of tetrahedral 
intermediate to create the acyl-imidazolium alkoxide zwitterions [65]. Figs. $7 \& 8$ represent the mechanism of $\mathrm{NHC}$ catalysed ROP and formation of zwitterion.

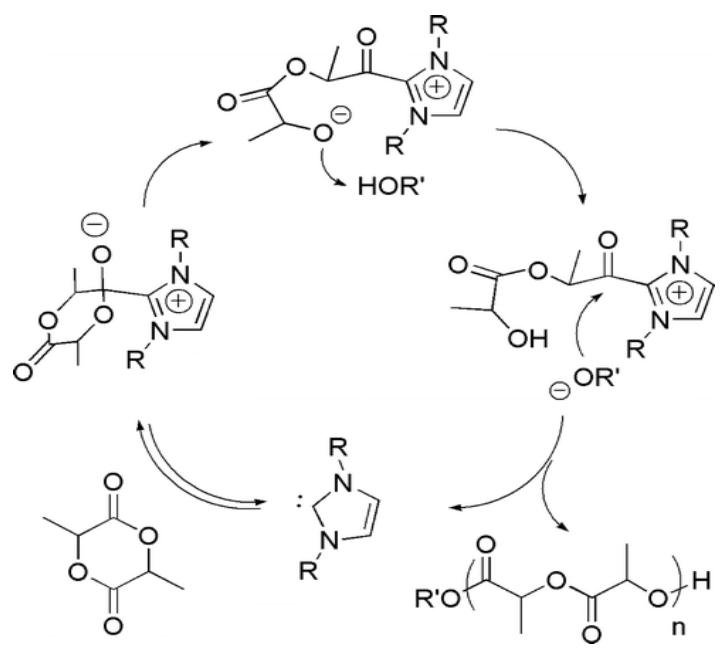

Fig. 7. Nucleophilic monomer-activated mechanism for ROP

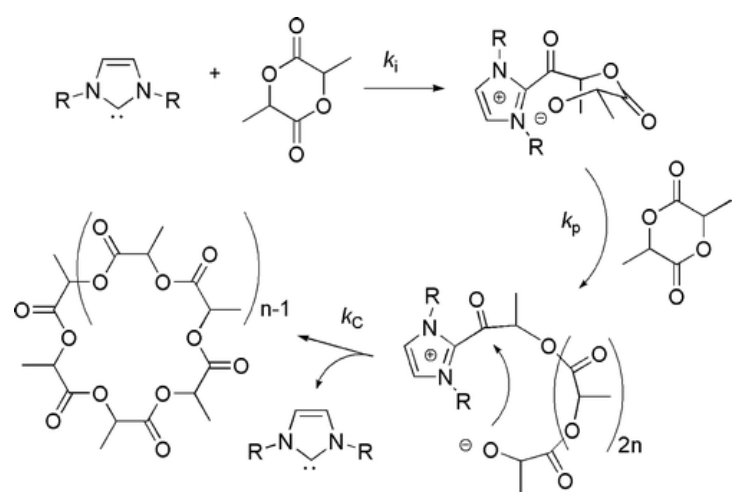

Fig. 8. Zwitterionic polymerization of LA

In 2013 Yan Wang et al. [7] contributed also in the field of organic catalysis of PLA by using $\mathrm{NHC}$ as a nucleophilic catalyst [10]. In their work, they investigated the influence of temperature, monomer/initiator molar ratio, monomer/catalyst molar ratio, monomer concentration, as well as polymerization time. In comparison with other catalysts especially the metal catalysts, carbine catalysts are inexpensive $[55,66]$, highly active and nontoxic in nature. Imidazolium-based carbenes are a reliable alternative to the metal catalysts. The activity and efficiency $\mathrm{NHC}$ have illustrated as superior organo-catalysts for polymerization [67]. Recent methods proposed by Wang et al. [7] and several others, defines the suitability of carbene catalyst to exclude the complexity by isolating sensitive carbene complex and to provide polymerization details [58,67-72]. Parameters such as monomer/initiator molar ratio $([\mathrm{M}] /[\mathrm{I}])$, monomer/catalyst molar ratio $([\mathrm{M}] /[\mathrm{C}])$ and monomer concentration affect the molecular weight and polydispersity of polymerization process significantly. Both the monomer conversion and molecular weight of PLA increase with an increase of LA concentration up to the saturation point and then starts decreasing.

The decrease in molecular weight at higher concentration happens because the active monomer chain centre cannot react timely with the monomer owing to the increase in the systems viscosity. The monomer/initiator molar ratio has been examined in details by Wang et al. [7]. It was observed that the molar ratio was relatively critical to prepare high yield and high molecular weight-[11,12]. Because of the availability of less active centre in the polymerization system, the polymerization process cannot continue while decreasing initiator amount. Yet increasing initiator content can favour a large number of shorter polymeric chains, thus decreasing the molecular weight of PLA. The amount of catalyst also affects the formation of active species directly and thus the monomer conversion. Further the polymerization temperature and time also significantly affect the ROP of LA. It was also found that rise in temperature enhances the rate of intermolecular trans-esterification and thermal degradation reaction and causes the decrease in molecular weight of PLA, whereas below $15^{\circ} \mathrm{C}$ the polymerization reaction proceeds slowly [13].

\subsection{ROP through Alternative Energies (Microwave, Ultrasound \& Laser) Incorporation}

Application of microwave heating to process chemical reactions has received increasing attention in the past few years. Due to its qualities such as high efficiency, the capability of uniform heating and reduced reaction time, the large number of chemical reactions, both organic and inorganic, undergo a significant increase in reaction speed due to microwave irradiation compared to the general methods for heatirradiation such as furnace chamber and LASER heating etc. Microwave-assisted ROP of polylactide. 
Microwave assisted ROP technology for LA emerges as a green method for chemical synthesis for PLA due to its high efficiency and homogeneous heating $[71,75,76,78,79,96]$. The first microwave-irradiated polymerization of $D, L-$ LA (was reported by Liu et al. $[73,74,77]$ ).

Zhang et al. [73] polymerized successfully the $\mathrm{D}, \mathrm{L}-\mathrm{LA}$ by using ethanol, $\mathrm{ZnO}, \mathrm{SnCl}_{2}$ and Cat-A as catalyst applying continuous microwave irradiation in less than an hour. $36 \%$ yield has been reported on the final synthesis process. On the other hand compared to conventional heating with the same experimental setup, the negligible non-thermal effect of microwave irradiation was revealed. Based on chemical bonding studies, LA molecule contains two polar carbonyl groups which provide a suitable site of dielectric heating by absorbing microwaves, because of this fact Liu et al. [73] investigated the ROP of D,L-lactide (DLLA) considering micro-wave irradiation for PLA synthesis [18]. The rough reaction scheme of microwave-assisted ROP of LA is in Fig. 9.<smiles>CC1OC(=O)C(C)OC1=O</smiles>

Fig. 9. Microwave-assisted ring-opening polymerization of lactide

For details in reaction procedure, a sample mixture of D,L-LA was prepared and mixed with $\mathrm{Sn}(\mathrm{Oct})_{2}$ after that the reaction mixture was treated with three vacuum-argon cycles to get rid of solvent. The reaction mixture was then irradiated with power levels of $2.45 \mathrm{GHz}$ through the microwave. The mixture irradiated with microwave then cooled down in dichloromethane and precipitated in methanol. The source of microwave energy has been used as a pulse source to irradiate the mixture for short times. Further the weight ratio of the precipitate of polymer to the monomer was considered to determine the yield of the conversion of the amount of LA into PLA. The precipitate obtained was verified as P-DLLA by means of $1 \mathrm{H}$ NMR spectroscopy and GPC test which were similar to those of an authorized PLA specimen. By measuring the weight average molecular weight $\left(\mathrm{M}_{\mathrm{w}}\right)$ and yield of the resultant P-DLLA at varied time intervals, the effect of microwave energy on the ROP of DLLA was investigated at different power levels $(170,255,340$, and $510 \mathrm{~W})$. With the help of detailed investigation, Liu et al. [73] proposed that the rate of polymerization step and the chain propagation of PDLLA were both enhanced significantly by an increase in the microwave power up to certain extant $[94,95]$.

\subsection{Ultrasound/UItrasonic Facilitated ROP of Lactide}

In literature, the use of UV and Ultrasound source is reported as an energy source for degradation of PLA chain. Work based on separation of PLA chain with their complex substituents called poly LA-co-glycolic acid using intense and targeted Ultrasound has also been reported in literature because of which, Ultrasound would be used as a relevant future $A E$ source for ROP process to provide considerable bond breaking energy to initiate the polymerization reaction [81]. Deng et al. [83] and Oster et al. [84] demonstrated the application of UV source for surface grafting polymerization in detail. Fig. 10. Dubey el al. [96,97] and coworkers also reveals the benefit of using ultrasound source within the reaction process in great details. The implementation of ultrasound source highlighted the major benefits in the reaction process and reaction output.

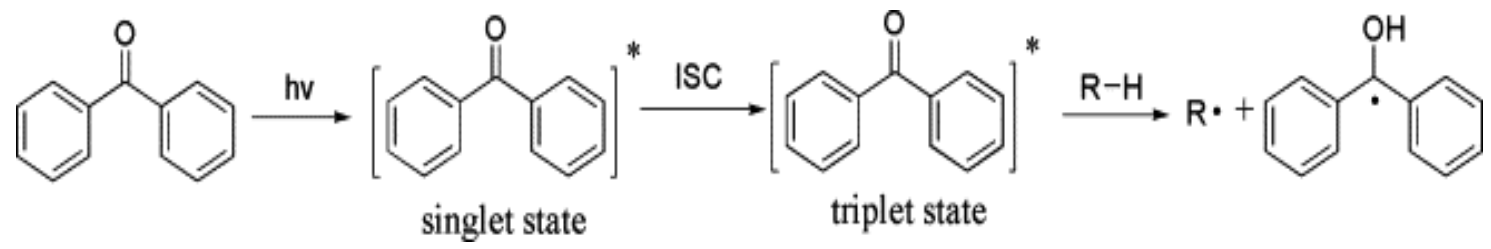

Fig. 10. Photo-grafting polymerization through UV radiation 


\subsection{ROP through Continuous Reactive Extrusion}

There are several polymer processing techniques like melt-blending, polymerization, branching, grafting and functionalization. Reactive extrusion (REx) is a cost effective method for these techniques on account of its low cost production and processing techniques $[85,86]$. Important features of extrusion polymerization are as following,

- Melt processing can be carried out in the solvent free medium. So the product can be easily isolated.

- There is a continuous process which starts from monomer and gets completed with the formation of polymer or final product.

- Residence time and residence time distribution can be controlled

- Several extrusion streams can be incorporated while running process

There are several benefits of the extruders in different applications such as deciding the grade of the mixing, proper control and higher conversion output. The effectiveness of the extruder is controlled by the geometry of the screws which are used in the extruder [86]. Residence time, power input and the scale of mixing to form melt in the extruder all are controlled by the screw size, geometry and rotating speed.

Various types of high molecular weight biodegradable polymers are prepared by ROP of cyclic ester through extruder polymerization such as poly( $\varepsilon$-caprolactone) (PCL) Fig. 11, polylactides (PLAs) and other aliphatic-aromatic poly-condensates as poly(butylene adipate-coterephtalate) [82]. By using reactive extrusion for ROP of several polymers at industrial level, it is possible to have control over polymerization, which is required to achieve desired molecular weights and suitable functional end groups [87].

Apart from PCL and PLAs, there are several other biodegradable aliphatic polyesters, for which traditional polycondensation method is used. One of such kind of polymer is poly(alkylene succinate) designed by Showa Denko, trademarked Bionolle ${ }^{\circledR}$ [88]. But due to relatively poor mechanical and high cost properties as compared to other polymers (polyethylene and polypropylene), the biodegradable copolyesters are still not very popular. It is possible to combine these biodegradable polymers with cheap inorganic (silicate type particles) or organic fillers (starch granules) to reduce the cost and to optimise the properties of aliphatic polyesters [86].

\subsection{ROP of PLA using Continuous Extrusion Reaction}

The current trend for the production of PLA at commercial level mostly supports the use of a continuous single-stage process reactive extrusion or twin screw extruder technology which satisfies both kinetic and thermal stability requirements [27]. For reactive extrusion polymerization, the use of purified form of LA is very significant. A mixture of $D$ or $L-L A L A$, stabiliser and the catalytic system is transferred continuously into a nitrogen purged material feeding unit. The crystalline powdery type LA is mixed with the catalyst such as stannous octoate dissolved in toluene. It is extracted later from the mixture using the vacuum. Design of the screw geometry widely influences the degree of mixing of PLA with other components and degree of mixing has huge impact on ROP of LA (Fig. 12).

The LA ROP proceeds through the 'coordination-insertion' mechanism by involving the cleavage of the particular oxygen-acyl cyclic ester monomer. It has been reported that the presence of one equimolar Lewis base such as triphenylphosphine along with 2-ethylhexanoic tin (II) salt $\left(\mathrm{Sn}(\mathrm{Oct})_{2}\right)$, significantly improves the LA polymerization rate. For the production of PLA the optical purity ( $D$ and $L$ type) of the reagent lactic acid is crucial because small amounts of enantiomer impurity change the properties such as crystallinity or biodegradation rate of polymerization. Another factor which affects the properties of the polymer is the detection and removal of impurities during reaction because impurities can easily change the intermediate reaction and product $[79,28]$. Dubey et al. [96,97] also revealed the reaction kinetic details of ROP process for PLA formation by considering a combination of the metal catalyst and $A E$ source in the extrusion reaction process. Fig. 13 represents the variation of conversion (X) and number average molecular weight $\overline{\mathrm{M}_{\mathrm{n}}}$ along the length of the screw (which in a continuous process can be correlated with time for the steady state) obtained with Ludovic $®$ [92,93], taking into account the effect of the polymerization. These results correspond to the simulation of the experiment with these initial conditions: temperature $(50-220)^{\circ} \mathrm{C}, \mathrm{AE}$ source (250-600) W, screw speed 300-600 rpm. Similar curves have been generated for each reactive extrusion experiment. 


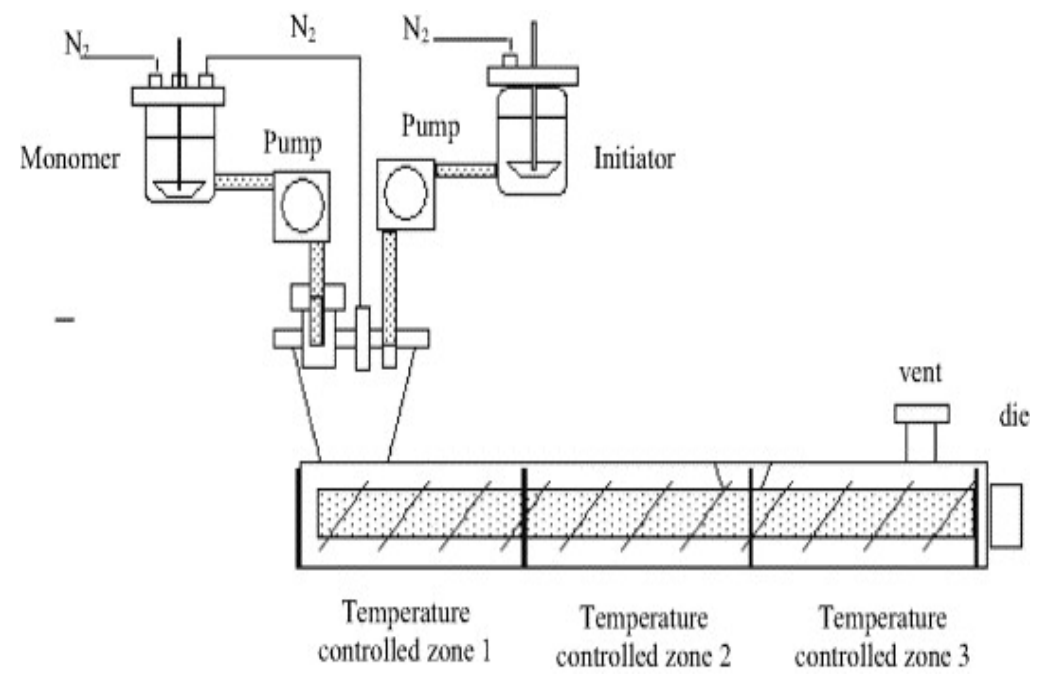

Fig. 11. Co-rotating twin-screw extruder for PCL polymerization

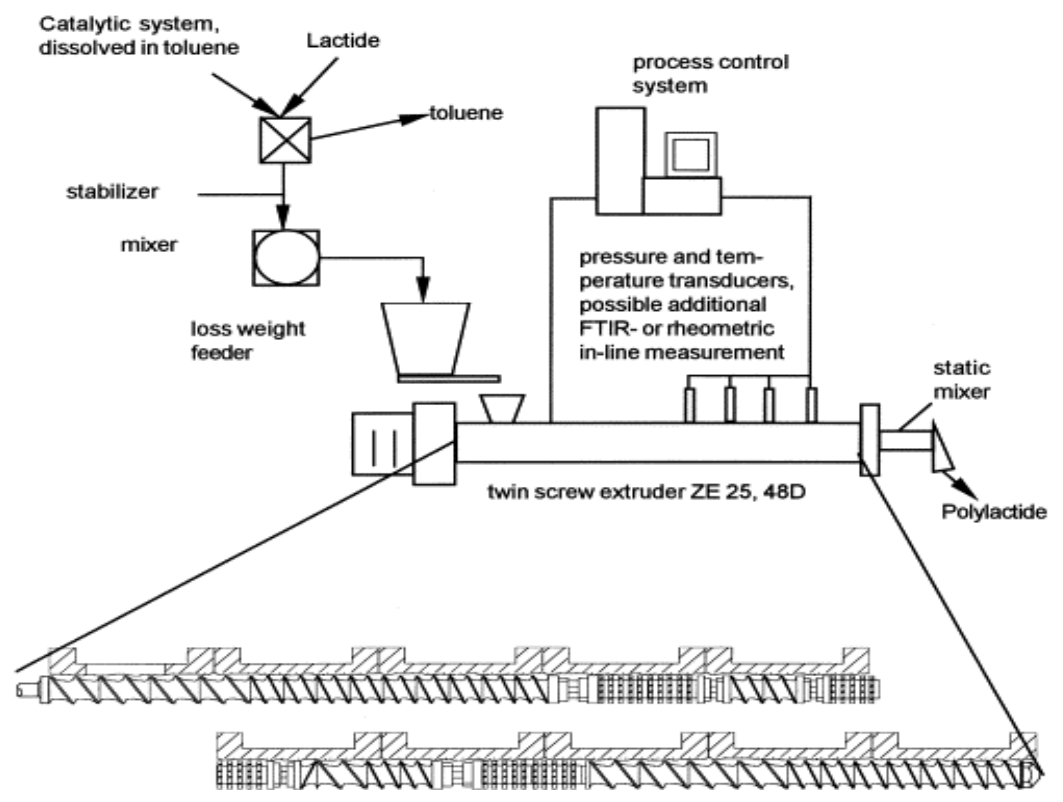

Fig. 12. Twin screw extruder

\section{INDUSTRIAL CONTRIBUTION PRODUCTION \\ CONCERN FOR}

The market for biodegradable and common household consumable polymers, such as PET, HIPP and PVC, has been approximately around 200,000 tons in 2005 , of which $50 \%$ was PLA. The demand for industrial production of biodegradable polymers instead of conventional petrochemical polymers increases many folds after the fact of environmental harm (landfilled) issues related to the petrochemical based polymers highlighted. Sven Jacobsen et al. [26] mentioned in an article mentioned that in the case of plastic waste, US alone produced 35 million tons of consumer polymers in 1998 whereas the corresponding figure of Europe and Asia were 34 million tons and 25 million tons. Since 2009, the total amount of plastic waste due post-consumer plastics which is plastic that can be "recycled" to reuse the material out of which they are made and to reduce the amount of waste going into landfills has been 


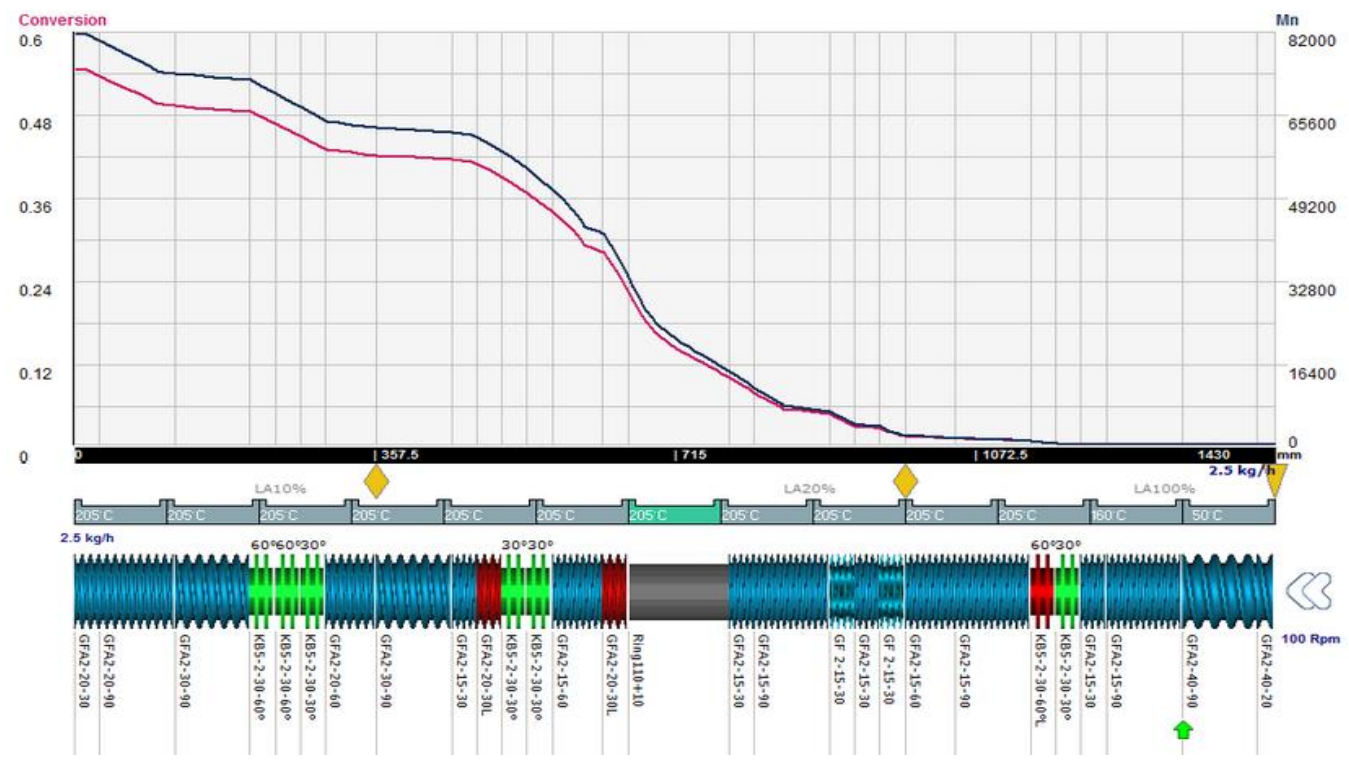

Fig. 13. (Mn ) (purple line) vs $T \& X$ (red line) vs $T$ obtained with Ludovic $\circledast$ for $T(50-220)^{\circ} \mathrm{C}$, $A E=250 \mathrm{~W}, 600 \mathrm{rpm}$

speeding in Europe but since 2011 it has remained the same, at about 25.2 million tonnes (2012). $77 \%$ of total waste was generated by the following seven countries: Germany, UK, France, Italy, Spain, Poland, and the Netherlands while the rest originated from the remaining 22 countries [89].

Commercial use of PLA has come into prominence in last 15 years because of its biodegradable and biocompatible nature and extensive application in the field of medical and clinical consumer products [46]. Lactic acids are the major component of the food-related application in USA and cover $85 \%$ of the commercial products [90]. The large production volume requires an economically viable manufacturing process. For large scale the metal-free and degradable commercial production, the continuous polymerization of PLA seems to be an essential and efficient way of production.

Based on quality and consumer requirements, several industrial processing methods such as reactive extrusion, injection moulding, injection stretch blow moulding, blown film, casting, thermoforming, foaming, fibre spinning, blending, batch process and compounding are employed to produce PLA $[18,19,22]$. The selection of initiator system, the catalyst concentration, monomer-to-initiator ratio, polymerization time and temperature change the property of the polymer. Initially, the ROP process of PLA was carried out in a batch process which contains several vessels to mix the initiator and the catalyst with monomer at the certain temperature. The commonly used solvent for the batch process is toluene. In modern age for higher yield and cost effectiveness, PLA production is mostly based on the process of reactive extrusion process through twin screw extruder $[9,38,86]$.

\section{KINETICS AND THEORETICAL MODELLING OF ROP MECHANISM}

In literature, several reaction mechanisms were proposed to describe the ROP process. To explain the interdependence of reaction parameters (monomer concentration, temperature, rate constants), reaction mechanisms were formulated by several groups in the form of ordinary differential equations [25, 30,32]. Different mathematical kinetic models have been proposed, but their number in comparison to experimental/empirical data is significantly less. To verify the experimental results theoretically, different groups adopted different mathematical techniques.

- Banu et al. [9] applied the least square method in their mathematical model to verify the reactive extrusion experimental work of ROP of LA using stannous octoate catalyst. The procedure was based on boundary value estimation function "bvp4c" using the software MATLAB. 
- Ryner et al. [68] and Lavan et al. [22] used the hybrid density functional method B3LYP, a quantum chemistry calculation using Gaussian software to calculate the geometries and energies which govern the thermodynamical properties of ROP of LA.

- $\mathrm{Yu}$, et al. [11,91] numerically solved the rate kinetics equation with the help of method of moments to verify the experimental work using stannous octoate as metallic catalyst. The method of moments is a technique for calculating estimators of the parameters that is based on matching the sample moments with the corresponding distribution moments.

- Dubey et al. [96] have solved the rate kinetic equations involved in ROP process of $L A$ in the presence of the metal catalyst and $A E$ source by using MATLAB tool.

- Dubey et al. [97] Revealed the reaction kinetic details of ROP process for PLA formation by considering the combination of the metal catalyst and AE source in the extrusion reaction process, which is one of its own kind of innovative work in this field.

In 2007 Mehta et al. [18] proposed detailed theoretical kinetic model of ROP of LA based on Dubois et al. [8] experimental work and results that were based on the use of aluminium isopropoxide as a catalyst. They formulated the reaction kinetics of $R O$ of PLA in the form of different first order ordinary differential equations. The ROP of LA consists of three basic stages (eq. 1-3) to complete the whole process that can be classified such as initiation, propagation, and termination [8]. The reaction mechanism is the following:

$$
\begin{array}{ll}
\mathrm{M}+\mathrm{I} \stackrel{\mathrm{K}_{0}}{\rightarrow} \mathrm{P}_{\mathrm{i}} & \text { (1) (Initiation) } \\
\mathrm{P}_{\mathrm{j}}+\mathrm{M} \stackrel{\mathrm{K}_{\mathrm{p}}}{\rightarrow} \mathrm{P}_{\mathrm{j}+1} & \text { (2) (Propagation) } \\
\mathrm{P}_{\mathrm{j}}+\mathrm{M} \stackrel{\mathrm{K}_{t}}{\rightarrow} \mathrm{M}_{\mathrm{j}}+\mathrm{P}_{1}
\end{array}
$$

Where $M, I$ and $P_{j}$ represent the monomer, initiator, and polymer chain of length $j$ and $K_{0}, K_{p}$ and $K_{t}$ represent initiation, propagation and termination rate constants.

The work reported that ROP of LA proceeds through "coordination-insertion" mechanism. They found that the polymerization is normally "living" until a certain molecular weight is reached. Kinetics of the LA polymerization has been investigated at $70^{\circ} \mathrm{C}$ and it was found to be first order [41]. In conclusion, the kinetics law proposed is mentioned below (4).

$-\frac{\mathrm{d}[\mathrm{LA}]}{\mathrm{dt}}=\mathrm{k}_{\mathrm{j}}[\mathrm{LA}]\left[\mathrm{Al}(\mathrm{OPr})_{3}\right]$

Where $[\mathrm{LA}]$ and $\left[\mathrm{Al}(\mathrm{OPr})_{3}\right]$ represents the concentration of LA monomer and the catalyst. $k_{j}$ stands for rate constant of the reaction.

To validate their theoretical model based on Dubois et al. [41] they proposed a set of ordinary differential equations (ODE) to consider the role of each reaction parameter in reaction kinetics. The mass balance equations for batch reactor were written for the above kinetic reaction (eq. 1-3) as follows (eq. 5-9):

$$
\begin{aligned}
& \frac{\mathrm{d}[\mathrm{M}]}{\mathrm{dt}}=-[\mathrm{M}]\left\{\mathrm{k}_{0}[\mathrm{I}]+\sum_{\mathrm{j}=1}^{\mathrm{n}} \mathrm{k}_{\mathrm{j}}\left[\mathrm{P}_{\mathrm{j}}\right]+\sum_{\mathrm{j}=1}^{\mathrm{n}} \mathrm{k}_{\mathrm{tj}}\left[\mathrm{P}_{\mathrm{j}}\right]\right\} \\
& \frac{\mathrm{dy}[\mathrm{I}]}{\mathrm{dt}}=-\mathrm{k}_{0}[\mathrm{I}][\mathrm{M}] \\
& \frac{\mathrm{d}\left[\mathrm{P}_{1}\right]}{\mathrm{dt}}=\mathrm{k}_{0}[\mathrm{I}][\mathrm{M}]-\mathrm{k}_{1}\left[\mathrm{P}_{1}\right][\mathrm{M}]+\sum_{\mathrm{j}=2}^{\mathrm{n}} \mathrm{k}_{\mathrm{tj}}\left[\mathrm{P}_{\mathrm{j}}\right][\mathrm{M}](7) \\
& \frac{\mathrm{d}[\mathrm{Pj}]}{\mathrm{dt}}=[\mathrm{M}]\left\{\mathrm{k}_{(\mathrm{j}-1)}\left[\mathrm{P}_{\mathrm{j}-1}\right]-\mathrm{kj}_{\mathrm{j}}\left[\mathrm{P}_{\mathrm{j}}\right]-\mathrm{k}_{\mathrm{tj}}\left[\mathrm{P}_{\mathrm{j}}\right]\right\}, \mathrm{j}>1 \\
& \frac{\mathrm{d}[\mathrm{M}]}{\mathrm{dt}}=\mathrm{k}_{\mathrm{tj}}\left[\mathrm{P}_{\mathrm{j}}\right][\mathrm{M}], \quad \mathrm{j} \geq 1
\end{aligned}
$$

Where: [M], $[I]$ and $\left[P_{j}\right]$ represents the concentration of monomer, initiator and polymer chain of length "j", and $k_{0}, k_{j}$ and $k_{t}$ represent the rate constant of initiation, propagation and termination reactions.

Mehta et al. [8] solved the above ODE rate equation by using multiple-step Euler method and verified the model with the help of Dubois et al. [41] experimental report [12]. For modelling the process, the maximum polymer chain length was considered to be 5000 repeating units. This was based on observations of experimental results [8]. In order to compare the output of the simulation at several monomers to initiator ratio with experimental data, the number average molecular weight $\left(M_{n}\right)$ was calculated using the following expressions (10):

$M_{n}=\frac{\sum_{j=1}^{n} j \cdot\left(\left[P_{j}\right]+\left[M_{j}\right]\right)}{\sum_{j=1}^{n}\left(\left[P_{j}\right]+\left[M_{j}\right]\right)}$

The comparison of the variation of number average molecular weight $(\mathrm{Mn})$ versus time is in Fig. 14.

Although the ROP of LA can be carried out using several catalysts, in order to obtain PLA in a 
continuous process using reactive extrusion, the bulk polymerisation has to be completed in a very short time (few minutes), which would be the residence time of the extrusion process. Therefore, ROP of LA using stannous octoate $\mathrm{Sn}(\mathrm{Oct})_{2}$ as the catalyst was selected because $\mathrm{Sn}(\mathrm{Oct})_{2}$ promotes fast LA polymerisation which results in higher molecular weight. However, when $\mathrm{Sn}(\mathrm{Oct})_{2}$ is used, side reactions (like transesterification and random chain scission reactions) occur even during any other melt processing [7].

In 2009 and later on in $2011 \mathrm{Yu}$ et al. [91] proposed a model which considered $\mathrm{Sn}(\mathrm{Oct})_{2}$ as a catalyst and 1-dodecanol as co-catalyst at a temperature range between 130 and $180^{\circ} \mathrm{C}$ to start the ROP of LA monomers [11,91]. Different monomer-to-catalyst and cocatalyst-to-catalyst ratio to investigate the proper reaction mechanism of ROP process were performed [11]. "Ester interchange" reactions, also called trans-esterification and non-radical random chain scission, were additionally considered to the Mehta et al. [91]. The reaction scheme proposed is shown in equations 11-19. In the reaction mechanism equation 11,12 and 13 represent initiation, propagation and termination reaction. Equations 14, 15 and 16 represent the transesterification reactions. The reactions 17,18 and 19 represent random chain scission.

$$
\begin{aligned}
& \mathrm{C}+\mathrm{D}_{\mathrm{n}} \underset{\mathrm{K}_{\mathrm{a} 2}}{\stackrel{\mathrm{K}_{\mathrm{a} 1}}{\rightleftharpoons}} \mathrm{R}_{\mathrm{n}}+\mathrm{A} \\
& \mathrm{R}_{\mathrm{n}}+\mathrm{M} \underset{\mathrm{K}_{\mathrm{d}}}{\stackrel{\mathrm{K}_{\mathrm{p}}}{\rightleftharpoons}} \mathrm{R}_{\mathrm{n}+2} \\
& \mathrm{R}_{\mathrm{n}}+\mathrm{D}_{\mathrm{i}} \underset{\mathrm{K}_{\mathrm{s}}}{\stackrel{\mathrm{K}_{\mathrm{s}}}{\rightleftharpoons}} \mathrm{R}_{\mathrm{i}}+\mathrm{D}_{\mathrm{n}} \\
& \mathrm{R}_{\mathrm{i}}+\mathrm{R}_{\mathrm{j}} \underset{\mathrm{K}_{\mathrm{te}}}{\rightleftharpoons} \mathrm{R}_{\mathrm{i}+\mathrm{j}-\mathrm{n}}+\mathrm{R}_{\mathrm{n}}
\end{aligned}
$$
previously proposed reaction mechanism of

Where: $k a_{1}, k a_{2}$ are the activation rate coefficients, $k_{p}, k_{d}$ are the propagation rate coefficients, $k s$ is the chain-transfer rate coefficient, $k_{t e}$ is the trans-esterification rate coefficient and $k_{d e}$ is the random chain scission reaction rate coefficient;

$C$ is the catalyst, $\mathrm{Sn}(\mathrm{Oct})_{2}, A$ is octanoic acid $(\mathrm{OctOH})$ produced by the catalyst, $R_{i}$ represents the active polymer chains with length " $i$ ", $D_{i}$ represents the dormant polymer chains with length "i", $G_{j}$ represents the terminated polymer chains with length " $\mathrm{j}$ " and $M$ the monomer.

To consider the effect of several reaction parameters on the proposed reaction mechanism, reaction equations 11-19 were formulated into mathematical equations (eq. 2025) which show the variation of several parameters with time.

$$
\begin{aligned}
& \frac{\mathrm{d}[\mathrm{C}]}{\mathrm{dt}}=-\mathrm{k}_{\mathrm{a} 1}[\mathrm{C}] \mu_{0}+\mathrm{k}_{\mathrm{a} 2}[\mathrm{~A}] \lambda_{0} \\
& \frac{\mathrm{d}[\mathrm{A}]}{\mathrm{dt}}=\mathrm{k}_{\mathrm{a} 1}[\mathrm{C}] \mu_{0}-\mathrm{k}_{\mathrm{a} 2}[\mathrm{~A}] \lambda_{0} \\
& \frac{\mathrm{dM}}{\mathrm{dt}}=-\mathrm{k}_{\mathrm{p}} M \lambda_{0}+\mathrm{k}_{\mathrm{d}}\left(\lambda_{0}-\mathrm{R}_{1}-\mathrm{R}_{0}\right)
\end{aligned}
$$

$$
\begin{aligned}
\frac{\mathrm{d}[\mathrm{Rn}]}{\mathrm{dt}}= & \mathrm{k}_{\mathrm{a} 1}\left[\mathrm{D}_{\mathrm{n}}\right][C]-\mathrm{k}_{\mathrm{a} 2}\left[\mathrm{R}_{\mathrm{n}}\right][\mathrm{A}]+\left(1-\delta_{\mathrm{n}, 0}\right)\left(1-\delta_{\mathrm{n}, 1}\right)\left(\mathrm{k}_{\mathrm{p}}\left[\mathrm{R}_{\mathrm{n}-2}\right][\mathrm{M}]-\mathrm{k}_{\mathrm{d}}\left[\mathrm{R}_{\mathrm{n}}\right]\right)+\mathrm{k}_{\mathrm{d}}\left[\mathrm{R}_{\mathrm{n}+2}\right]-\mathrm{k}_{\mathrm{p}}\left[\mathrm{R}_{\mathrm{n}}\right][\mathrm{M}]-\mathrm{k}_{\mathrm{s}}\left[\mathrm{R}_{\mathrm{n}}\right] \mu_{0}+\mathrm{k}_{\mathrm{s}}\left[\mathrm{D}_{\mathrm{n}}\right] \lambda_{0} \\
- & \mathrm{k}_{\mathrm{te}}\left\{\left[\mathrm{R}_{\mathrm{n}}\right]\left(\lambda_{1}-\lambda_{0}+\mathrm{R}_{0}\right)-\left(1-\delta_{\mathrm{n}, 0}\right) \lambda_{0} \sum_{\mathrm{j}=\mathrm{n}+1}^{\infty}\left[\mathrm{R}_{\mathrm{j}}\right]+\left(1-\delta_{\mathrm{n}, 0)}\left(1-\delta_{\mathrm{n}, 1}\right)(\mathrm{n}-1)\left[\mathrm{R}_{\mathrm{n}}\right] \lambda_{0}-\left(1-\delta_{\mathrm{n}, 0}\right) \sum_{\mathrm{i}=0}^{\mathrm{n}-1}\left[\mathrm{R}_{\mathrm{i}}\right] \sum_{\mathrm{k}=\mathrm{n}+1-\mathrm{i}}^{\infty}\left[\mathrm{R}_{\mathrm{k}}\right]\right.\right. \\
& +\left[\mathrm{R}_{\mathrm{n}}\right]\left(\mu_{1-}-\mu_{0}+\mathrm{D}_{0}\right)-\left(1-\delta_{\mathrm{n}, 0}\right) \lambda_{0} \sum_{\mathrm{i}=\mathrm{n}+1}^{\infty}\left[\mathrm{D}_{\mathrm{i}}\right]+\left[\mathrm{R}_{\mathrm{n}}\right]\left(\mathrm{Y}_{1}-\mathrm{V}_{0}+\mathrm{G}_{0}\right) \\
- & \left.\left(1-\delta_{\mathrm{n}, 0}\right) \lambda_{0} \sum_{\mathrm{i}=\mathrm{n}+1}^{\infty}\left[\mathrm{G}_{\mathrm{i}}\right]\right\}-\mathrm{kde}(\mathrm{n}-1)\left[\mathrm{R}_{\mathrm{n}}\right]+\mathrm{kde} \sum_{\mathrm{i}=\mathrm{n}+1}^{\infty}\left[\mathrm{R}_{\mathrm{i}}\right] \\
\frac{\mathrm{d}[\mathrm{Dn}]}{\mathrm{dt}}= & -\mathrm{k}_{\mathrm{a} 1}\left[\mathrm{D}_{\mathrm{n}}\right][\mathrm{C}]+\mathrm{k}_{\mathrm{a} 2}\left[\mathrm{R}_{\mathrm{n}}\right][\mathrm{A}]+\mathrm{k}_{\mathrm{s}}\left[\mathrm{R}_{\mathrm{n}}\right] \mu_{0}-\mathrm{k}_{\mathrm{s}}\left[\mathrm{D}_{\mathrm{n}}\right] \lambda_{0}+\mathrm{k}_{\mathrm{te}}\left(1-\delta_{\mathrm{n}, 0}\right) \sum_{\mathrm{i}=0}^{\mathrm{n}-1}\left[\mathrm{R}_{\mathrm{i}}\right] \sum_{\mathrm{k}=\mathrm{n}+1-\mathrm{i}}^{\infty}\left[\mathrm{D}_{\mathrm{k}}\right] \\
& \quad-\mathrm{k}_{\mathrm{te}}\left(1-\delta_{\mathrm{n}, 0}\right)\left(1-\delta_{\mathrm{n}, 1}\right)(\mathrm{n}-1)\left[\mathrm{D}_{\mathrm{n}}\right] \lambda_{0}-\mathrm{k}_{\mathrm{de}}(\mathrm{n}-1)\left[\mathrm{D}_{\mathrm{n}}\right]+\mathrm{k}_{\mathrm{de}} \sum_{\mathrm{i}=\mathrm{n}+1}^{\infty}\left[\mathrm{D}_{\mathrm{i}}\right] \\
\frac{\mathrm{d}[\mathrm{Gk}]}{\mathrm{dt}}= & \mathrm{k}_{\mathrm{te}}\left(1-\delta_{\mathrm{n}, 0}\right) \lambda_{0} \sum_{\mathrm{i}=\mathrm{n}+1}^{\infty}\left[\mathrm{G}_{\mathrm{i}}\right]-\mathrm{k}_{\mathrm{te}}\left(1-\delta_{\mathrm{n}, 0}\right)\left(1-\delta_{\mathrm{n}, 1}\right)(\mathrm{n}-1)\left[\mathrm{G}_{\mathrm{n}}\right] \lambda_{0--} 2 \mathrm{k}_{\mathrm{de}}\left(1-\delta_{\mathrm{n}, 0}\right)\left(1-\delta_{\mathrm{n}, 1}\right)(\mathrm{n}-1)\left[\mathrm{G}_{\mathrm{n}}\right] \\
& +2 \mathrm{k}_{\mathrm{de}}\left(1-\delta_{\mathrm{n}, 0}\right) \sum_{\mathrm{m}=\mathrm{n}+1}^{\infty}\left[\mathrm{G}_{\mathrm{m}}\right]+\mathrm{k}_{\mathrm{de}}\left(1-\delta_{\mathrm{n}, 0}\right) \sum_{\mathrm{k}=\mathrm{n}+1}^{\infty}\left[\mathrm{R}_{\mathrm{k}}\right]+\mathrm{k}_{\mathrm{de}}\left(1-\delta_{\mathrm{n}, 0}\right) \sum_{\mathrm{k}=\mathrm{n}+1}^{\infty}\left[\mathrm{D}_{\mathrm{k}}\right]
\end{aligned}
$$


Equations 20-22 are the material balances of the monomeric species present in the kinetic model equations 11-19. Equations 23-25 are population balances of all active, dormant and terminated chains, respectively, considering reversible activation, propagation, chain transfer, intermolecular trans-esterification, and the newly developed irreversible termination, random chain scission [11].

In order to compare the output of the developed kinetic model at several monomers to initiator ratio with experimental data, $\mathrm{Yu}$ et al. [91] calculated the number average molecular weight $(\mathrm{Mn})$ for different initial conditions [11]. The variation of $\mathrm{Mn}$ versus time (Fig. 15) shows the significance of several stages of reaction mechanism. The initial variation up to $0.01 \mathrm{~h}$ shows the dominance of initiation process on rate of reaction. At $0.02 \mathrm{~h}$ propagation starts and at the saturation point $0.1 \mathrm{~h}$ shows the termination state of the ROP process [11]. The final stage includes all the side reactions, trans-esterification and scission which suffice the termination reaction at the end.

A detailed model of L-LA polymerization at different temperature using $\mathrm{Sn}(\mathrm{Oct})_{2}$ as the catalyst and 1-dodecanol as cocatalyst was developed. The model considered the effect of inter and intramolecular transesterification reactions. The validation of the model was carried out by comparison with experimental data at the different monomer to catalyst ratio and catalyst to cocatalyst ratio. The reaction responsible for the decrease of molecular weight

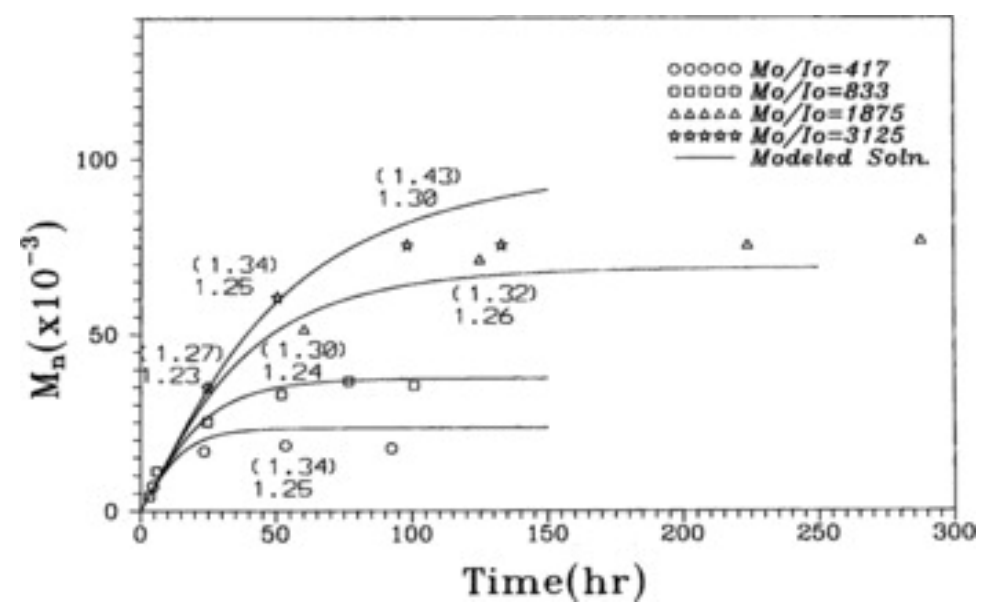

Fig. 14. A comparison of experimental [41] and modelling results (number average molecular weight) for the polymerization of (D, L)-Lactide. The solid lines are the solutions obtained from the model and points are the experimental values
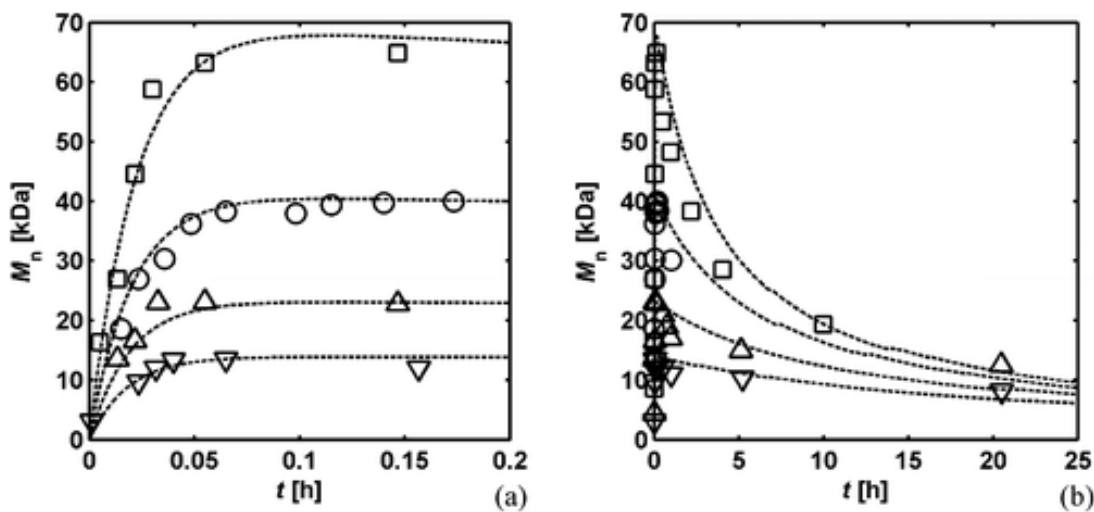

Fig. 15. Number average weight (Mn) for ROP of LA with $\mathrm{Sn}(\mathrm{Oct})_{2}$ and 1-dodecanol at $180^{\circ} \mathrm{C}$, $[\mathrm{M}]_{0} /[\mathrm{C}]_{0}=10000$ and $[\mathrm{OH}]_{0} /[\mathrm{C}]_{0}=20 \square 34,060, \Delta 100, \nabla$ experimental results in dots and simulated results with dashed lines 
at high temperature is mentioned at random chain scission. Satisfactory prediction of MWD was achieved when both transesterification and random chain scission were included in the kinetic scheme. The overall average errors of the model predictions at the different condition in comparison to experimental data are well below $5 \%$.

\section{CONCLUSION}

Synthesis of PLA from LA monomers through ROP process using the metal catalyst is the standard industrial process and it leads to throughputs of up to $20 \mathrm{~kg} / \mathrm{hr}$ Although PLA can boast of its eco-credentials, it can be toxic. The health and environmental hazards may emanate from traces of the metal catalyst that are left behind in the polymer after the polymerisation of PLA. In order to produce non-toxic PLA, the metal catalyst can be replaced with organic and/or metal-free catalyst. Several studies have explored this possibility, but unfortunately, they obtained low conversion rates and PLA with low molecular weight. Also, the maximum throughput was about 2-3 kg/hr, much lower than the industrially sustainable/commercially viable rate of $20 \mathrm{~kg} / \mathrm{hr}$.

For the production of safer and cleaner PLA polymer from lab scale to industrial scale, further investigations will be required which includes large-scale computational simulation too. Research which involves the experimental and theoretical investigation of PLA synthesis considering the non-metal and alternative energy in the reaction seems to be an effective mechanism to focus on. Theoretical modelling and simulation are useful to provide an estimate of the throughput and help to plan the experimental/industrial production accordingly.

Groups such as InnoREX consortium (www.InnoREX.eu) are performing detailed step by step investigations of above-defined mechanism to achieve highly precise, controlled and large scale synthesis of PLA through the reactive extrusion process. The group is working on considering the impact of replacing the metal catalyst with organic one as well implementation of $A E$ sources in the reaction process. To achieve this target lab scale experiments and mathematical simulation model to verify the output of the reaction are being performed. To consider the impact of $\mathrm{AE}$ sources and to study the production quality/market demands of PLA (Medical, Electronic \& Food Packaging), several industrial partners also involved in InnoREX group. The InnoREX group is not the only one interested in a safer and notoxic method to prepare PLA. Many experts from industries like Purac and Naturework limited are also trying to develop a novel reactor concept using continuous, highly precise and controlled metal-free polymerisation of PLA.

\section{ACKNOWLEDGEMENT}

S.P.D. wish to acknowledge the financial support provided by European Commission (FP7 InnoREX project grant number: 309802). The authors also gratefully acknowledge support from Cranfield University, School of Aerospace, Transport, and Manufacturing (SATM) to provide place and support to conduct the research, partners and members of www.InnoREX.eu group to provide details of the investigation of PLA research.

\section{COMPETING INTERESTS}

Authors have declared that no competing interests exist.

\section{REFERENCES}

1. Amass W, Amass A, Tighe B. A review of biodegradable polymers: Uses, current developments in the synthesis and characterization of biodegradable polyesters, blends of biodegradable polymers and recent advances in biodegradation studies. Polym. Int. 1998;47(2):89-144.

2. Jacobsen $S$, Fritz HG, Degée $P$, Dubois $P$, Jérôme $R$. Continuous reactive extrusion polymerisation of L-LA - an engineering view. Macromol. Symp. 2000;153(1):261273.

3. Arshak K, Velusamy V, Korostynska O, Oliwa-Stasiak K, Adley C. Conducting polymers and their applications to biosensors: Emphasizing on food borne pathogen detection. IEEE Sens. J. 2009;9(12):1942-1951.

4. Cohn D, Younes H, Uretzky G. Biodegradable polymeric materials based on polyether glycols, processes for 
the preparation thereof and surgical articles made there from. 1989;4826945.

5. Başaran I, Oral A. Synthesis and characterization of poly(L-lactic acid)/clay nanocomposite via metal-free process. Polym.-Plast. Technol. Eng. 2013;52(12): 1271-1276.

6. Kamber NE, Jeong W, Waymouth RM, Pratt RC, Lohmeijer BGG, Hedrick JL. Organocatalytic

polymerization. Chem. Rev. 2007; 107(12):5813-5840.

7. Wang $Y$, Zhang L, Guo X, Zhang R, Li J. Characteristics and mechanism of $\mathrm{L}$ lactide polymerization using $\mathrm{N}$-heterocyclic carbene organocatalyst. J. Polym. Res. 2013;20(3).

8. Mehta R, Kumar V, Bhunia H, Upadhyay SN. Synthesis of poly(lactic acid): A review. J. Macromol. Sci. Part C Polym. Rev. 2005;45(4):325-349.

9. Banu I, Puaux JP, Bozga G, Nagy I. Modeling of I-lactide polymerization by reactive extrusion. Macromol. Symp. 2010; 289(1):108-118.

10. Gu S, Yang M, Yu T, Ren T, Ren J. Synthesis and characterization of biodegradable lactic acid-based polymers by chain extension. Polym. Int. 2008;57(8):982-986.

11. $\mathrm{Yu} Y$, Storti $G$, Morbidelli M. Kinetics of ring-opening polymerization of I,I-lactide. Ind. Eng. Chem. Res. 2011;50(13):79277940.

12. Odian GG. Principles of polymerization, 4th ed. Hoboken, N.J: Wiley-Interscience; 2004.

13. Carothers WH, Natta FJV. Studies on polymerization and ring formation. III. Glycol esters of carbonic acid. J. Am. Chem. Soc. 1930;52(1):314-326.

14. Carothers WH, Dorough GL, van Natta FJ. Studies of polymerization and ring formation. $X$. The reversible polymerization of six membered cyclic esters. J. Am. Chem. Soc. 1932;54(2):761-772.

15. Matsuo J, Aoki K, Sanda F, Endo T. Substituent effect on the anionic equilibrium polymerization of sixmembered cyclic carbonates. Macromolecules. 1998;31(14):4432-4438.

16. Keul H, Bächer R, Höcker H. Anionic ringopening polymerization of 2,2dimethyltrimethylene carbonate.
Makromol. Chem. 1986;187(11):25792589.

17. Sarel S, Pohoryles LA. The stereochemistry and mechanism of reversible polymerization of 2,2disubstituted 1,3-propanediol carbonates. J. Am. Chem. Soc. 1958;80(17):45964599.

18. Ariga T, Takata T, Endo T. Cationic ringopening polymerization of cyclic carbonates with alkyl halides to yield polycarbonate without the ether unit by suppression of elimination of carbon dioxide1. Macromolecules. 1997;30(4): 737-744.

19. Kricheldorf HR, Berl M, Scharnagl N. Poly(lactones). $\quad 9 . \quad$ polymerization mechanism of metal alkoxide initiated polymerizations of lactide and various lactones. Macromolecules. 1988; 21(2):286-293.

20. Albertsson AC, Sjoling M. Homopolymerization of 1,3-dioxan-2-one to high molecular weight poly(trimethylene carbonate). J. Macromol. Sci. Chem. 1992;A29(1):43-54.

21. Kricheldorf HR, Jenssen J, KreiserSaunders I. Polymers of carbonic acid, 6. Polymerization of trimethylene carbonate (1,3-dioxan-2-one) with complexation catalysts. Makromol. Chem. 1991; 192(10):2391-2399.

22. Al-Azemi TF, Bisht KS. Synthesis of novel bis- and tris-(cyclic carbonate)s and their use in preparation of polymer networks. Polymer. 2002;43(8):2161-2167.

23. Flory PJ. Molecular size distribution in ethylene oxide polymers. J. Am. Chem. Soc. 1940;62(6):1561-1565.

24. Vinogradova LV, Zgonnik VN, Il'ina AA, Docheva D, Tsvetanov C. Anionic polymerization in oxiranes. Polymerization of methyl methacrylate and 2-vinylpyridine in ethylene oxide. Macromolecules. 1992;25(25):6733-6738.

25. Brocas AL, Mantzaridis C, Tunc D, Carlotti S. Polyether synthesis: From activated or metal-free anionic ring-opening polymerization of epoxides to functionalization. Prog. Polym. Sci. 2013;38(6):845-873.

26. Fahlén J, Martinsson R, Midelf B. Allaround performance - New polycarbonate macrodiols extend the property range of PUD coatings. Eur. Coat. J. 2007;6:28-32. 
27. Kobayashi S. Enzymatic ring-opening polymerization of lactones by lipase catalyst: Mechanistic aspects. Macromol. Symp. 2006;240(1):178-185.

28. Dove AP. Organic catalysis for ringopening polymerization. ACS Macro Lett. 2012;1(12):1409-1412.

29. Tempelaar S, Mespouille L, Coulembier O, Dubois P, Dove AP. Synthesis and postpolymerisation modifications of aliphatic poly(carbonate)s prepared by ring-opening polymerisation. Chem. Soc. Rev. 2013;42(3):1312-1336.

30. Cambou B, Klibanov AM. Preparative production of optically active esters and alcohols using esterase-catalyzed stereospecific transesterification in organic media. J. Am. Chem. Soc. 1984; 106(9):2687-2692.

31. Margolin AL, Crenne JY, Klibanov AM. Stereoselective oligomerizations catalyzed by lipases in organic solvents. Tetrahedron Lett. 1987;28(15):1607-1609.

32. Abramowicz DA, Keese CR. Enzymatic transesterifications of carbonates in waterrestricted environments. Biotechnol. Bioeng. 1989;33(2):149-156.

33. Gross RA, Kalra B. Biodegradable polymers for the environment. Science. 2002;297(5582):803-807.

34. Knani D, Gutman AL, Kohn DH. Enzymatic polyesterification in organic media. Enzyme-catalyzed synthesis of linear polyesters. I. Condensation polymerization of linear hydroxyesters. II. Ring-opening polymerization of $\epsilon$-caprolactone. J. Polym. Sci. Part Polym. Chem. 1993;31(5):12211232.

35. Parmar VS, Bisht KS, Singh A, Jha A. Chiral discrimination by hydrolytic enzymes in the synthesis of optically pure materials. J. Chem. Sci. 1996;108(6):575583.

36. Kricheldorf HR, Sumbél M. Polylactones18. Polymerization of I,I-lactide with $\mathrm{Sn}(\mathrm{II})$ and Sn(IV) halogenides. Eur. Polym. J. 1989;25(6):585-591.

37. Singh V, Tiwari M. Structure-processingproperty relationship of poly(glycolic acid) for drug delivery systems 1: Synthesis and catalysis. Int. J. Polym. Sci. 2010;2010.

38. Puaux JP, Banu I, Nagy I, Bozga G. A study of l-lactide ring-opening polymerization kinetics. Macromol. Symp. 2007;259(1):318-326.
39. NatureWorks LLC Home Page. Available:http://www.natureworksllc.com/

40. Purac home.

Available:http://www.purac.com/

41. Dubois $P$, Jacobs $C$, Jerome $R$, Teyssie $P$. Macromolecular engineering of polylactones and polylactides. 4. Mechanism and kinetics of lactide homopolymerization by aluminum isopropoxide. Macromolecules. 1991;24(9):2266-2270.

42. Witzke DR, Narayan R, Kolstad JJ. Reversible kinetics and thermodynamics of the homopolymerization of I-lactide with 2ethylhexanoic acid tin(ii) salt. Macromolecules. 1997;30(23):7075-7085.

43. Robert JL, Aubrecht KB. Ring-opening polymerization of lactide to form a biodegradable polymer. J. Chem. Educ. 2008;85(2):258.

44. Mehta R, Kumar V, Upadhyay SN. Mathematical modeling of the poly(lactic acid) ring-opening polymerization kinetics. Polym.-Plast. Technol. Eng. 2007;46(3):257-264.

45. Enders D, Niemeier $O$, Henseler $A$. Organocatalysis by $n$-heterocyclic carbenes. Chem. Rev. 2007; 107(12):5606-5655.

46. InnoREX.

Available:http://www.innorex.eu/about.php

47. Coulembier O, Lohmeijer BGG, Dove AP, Pratt RC, Mespouille L, Culkin DA, Benight SJ, Dubois P, Waymouth RM, Hedrick JL. Alcohol adducts of n-heterocyclic carbenes: Latent catalysts for the thermally-controlled living polymerization of cyclic esters. Macromolecules. 2006;39(17):5617-5628.

48. Gold L. Statistics of polymer molecular size distribution for an invariant number of propagating chains. J. Chem. Phys. 2004;28(1):91-99.

49. Myers M, Connor EF, Glauser T, Möck A, Nyce G, Hedrick JL. Phosphines: Nucleophilic organic catalysts for the controlled ring-opening polymerization of lactides. J. Polym. Sci. Part Polym. Chem. 2002;40(7):844-851.

50. Dalko PI, Moisan L. Enantioselective organocatalysis. Angew. Chem. Int. Ed. 2001;40(20):3726-3748.

51. Pratt RC, Lohmeijer BGG, Long DA, Waymouth RM, Hedrick JL. 
Triazabicyclodecene: A simple bifunctional organocatalyst for acyl transfer and ringopening polymerization of cyclic esters. J. Am. Chem. Soc. 2006;128(14):45564557.

52. Vedejs E, Diver ST. Tributylphosphine: A remarkable acylation catalyst. J. Am. Chem. Soc. 1993;115(8):3358-3359.

53. Ragnarsson U, Grehn L. Novel amine chemistry based on DMAP-catalyzed acylation. Acc. Chem. Res. 1998;31(8): 494-501.

54. Tsuji H, Ikada Y. Properties and morphology of poly(l-lactide) 4 . Effects of structural parameters on long-term hydrolysis of poly(l-lactide) in phosphatebuffered solution. Polym. Degrad. Stab. 2000;67(1):179-189.

55. Csihony S, Culkin DA, Sentman AC, Dove AP, Waymouth RM, Hedrick JL. Singlecomponent catalyst/initiators for the organocatalytic ring-opening polymerization of lactide. J. Am. Chem. Soc. 2005;127(25):9079-9084.

56. Vedejs E, Rozners E. Parallel kinetic resolution under catalytic conditions: $A$ three-phase system allows selective reagent activation using two catalysts. J. Am. Chem. Soc. 2001;123(10):2428-2429.

57. Breslow R. On the mechanism of thiamine action. IV.1 Evidence from studies on model systems. J. Am. Chem. Soc. 1958;80(14):3719-3726.

58. Enders D, Balensiefer T. Nucleophilic carbenes in asymmetric organocatalysis. Acc. Chem. Res. 2004;37(8):534-541.

59. Dorgan JR, Lehermeier $H$, Mang $M$. Thermal and rheological properties of commercial-grade poly(lactic acid)s. J. Polym. Environ. 2000;8(1):1-9.

60. Dalko PI, Moisan L. In the golden age of organocatalysis. Angew. Chem. Int. Ed. 2004;43(39):5138-5175.

61. Jeong W, Hedrick JL, Waymouth RM. Organic spirocyclic initiators for the ringexpansion polymerization of $\beta$-lactones. J. Am. Chem. Soc. 2007;129(27):8414-8415.

62. Williams CK, Breyfogle LE, Choi SK, Nam W, Victor G. Young, Hillmyer MA, Tolman WB. A highly active zinc catalyst for the controlled polymerization of lactide. J. Am. Chem. Soc. 2003;125(37):1135011359.

63. Chamberlain BM, Cheng $M$, Moore DR, Ovitt TM, Lobkovsky EB, Coates GW.
Polymerization of lactide with zinc and magnesium $\beta$-diiminate complexes: Stereocontrol and mechanism. J. Am. Chem. Soc. 2001;123(14):3229-3238.

64. Duong HA, Tekavec TN, Arif AM, Louie J. Reversible carboxylation of $\mathrm{N}$-heterocyclic carbenes. Chem. Commun. 2004;1:112113.

65. Reynolds NT, Read de Alaniz J, Rovis T. Conversion of a-haloaldehydes into acylating agents by an internal redox reaction catalyzed by nucleophilic carbenes. J. Am. Chem. Soc. 2004;126(31):9518-9519.

66. Nyce GW, Glauser T, Connor EF, Möck A, Waymouth RM, Hedrick JL. In situ generation of carbenes: A general and versatile platform for organocatalytic living polymerization. J. Am. Chem. Soc. 2003; 125(10):3046-3056.

67. Thillaye du Boullay O, Marchal E, MartinVaca B, Cossío FP, Bourissou D. An activated equivalent of lactide toward organocatalytic ring-opening polymerization. J. Am. Chem. Soc. 2006; 128(51):16442-16443.

68. Ryner M, Stridsberg K, Albertsson AC, von Schenck H, Svensson M. Mechanism of ring-opening polymerization of 1,5dioxepan-2-one and I-lactide with stannous 2-ethylhexanoate. A theoretical study. Macromolecules. 2001;34(12)3877-3881.

69. Viciu MS, Grasa GA, Nolan SP. Catalytic dehalogenation of aryl halides mediated by a palladium/imidazolium salt system. Organometallics. 2001;20(16):3607-3612.

70. Cazin CSJ. N-Heterocyclic carbenes in transition metal catalysis and organocatalysis. Springer; 2010.

71. Cheng Z, Zhu X, Zhou N, Zhu J, Zhang Z. Atom transfer radical polymerization of styrene under pulsed microwave irradiation. Radiat. Phys. Chem. 2005;72(6):695-701.

72. Li J, Zhu X, Zhu J, Cheng Z. Microwaveassisted nitroxide-mediated radical polymerization of styrene. Radiat. Phys. Chem. 2006;75(2):253-258.

73. Liu LJ, Zhang C, Liao LQ, Wang XL, Zhuo RX. Microwave-assisted polymerization of $D$, L-lactide with stannous octanoate as catalyst. Chin. Chem. Lett. 2001;12(8):663-664.

74. Wiesbrock F, Hoogenboom R, Schubert US. Microwave-assisted polymer 
synthesis: State-of-the-art and future perspectives. Macromol. Rapid Commun. Oct. 2004;25(20):1739-1764.

75. "MicroCures, Inc."

Available:http://www.microcures.com/

76. Albert $P$, Warth $H$, Mülhaupt $R$, Janda $R$. Comparison of thermal and microwaveactivated polymerization of $\varepsilon$-caprolactone with titanium tetrabutylate as catalyst. Macromol. Chem. Phys. 1996; 197(5):1633-1641.

77. Liao LQ, Liu LJ, Zhang C, He F, Zhuo RX. Heating characteristics and polymerization of $\varepsilon$-caprolactone under microwave irradiation. J. Appl. Polym. Sci. 2003; 90(10):2657-2664.

78. Koroskenyi B, McCarthy SP. Microwaveassisted solvent-free or aqueous-based synthesis of biodegradable polymers. J. Polym. Environ. 2002;10(3):93-104.

79. Fang $X$, Simone $C D$, Vaccaro $E$, Huang SJ, Scola DA. Ring-opening polymerization of $\epsilon$-caprolactam and $\epsilon$ caprolactone via microwave irradiation. J. Polym. Sci. Part Polym. Chem. 2002;40(14):2264-2275.

80. Paulus RM, Becer CR, Hoogenboom R, Schubert US. Acetyl halide initiator screening for the cationic ring-opening polymerization of 2-ethyl-2-oxazoline. Macromol. Chem. Phys. 2008;209(8):794800.

81. Crivello JV. UV and electron beaminduced cationic polymerization. Nucl. Instrum. Methods Phys. Res. Sect. B Beam Interact. Mater. At. 1999;151(14):8-21.

82. Dash TK, Konkimalla VB. Polymeric modification and its implication in drug delivery: Poly- $\varepsilon$-caprolactone $(\mathrm{PCL})$ as a model polymer. Mol. Pharm. 2012;9(9): 2365-2379.

83. Deng J, Wang L, Liu L, Yang W. Developments and new applications of UV-induced surface graft polymerizations. Prog. Polym. Sci. 2009;34(2):156-193.

84. Oster G, Shibata O. Graft copolymer of polyacrylamide and natural rubber produced by means of ultraviolet light. J. Polym. Sci. 1957;26(113):233-234.

85. Kye H, White JL. Continuous polymerization of caprolactam in a modular intermeshing corotating twin screw extruder integrated with continuous melt spinning of polyamide 6 fiber: Influence of screw design and process conditions. J. Appl. Polym. Sci. 1994;52(9):12491262.

86. Raquez JM, Degée $P$, Nabar $Y$, Narayan $R$, Dubois P. Biodegradable materials by reactive extrusion: From catalyzed polymerization to functionalization and blend compatibilization. Comptes Rendus Chim. 2006;9(11-12):1370-1379.

87. Mecerreyes $D$, Jérôme $R$, Dubois $P$. Novel macromolecular architectures based on aliphatic polyesters: Relevance of the 'coordination-insertion' ring-opening polymerization. In Macromolecular Architectures, P. J. G. Hilborn, P. Dubois, C. J. Hawker, J. L. Hedrick, J. G. Hilborn, R. Jérôme, J. Kiefer, J. W. Labadie, D. Mecerreyes, and W. Volksen, Eds. Springer Berlin Heidelberg. 1-59.

88. "Starcla -Bio-based Bionolle resin. Available:http://www.showa-

denko.com/index.php?id $=6 \& L=1 \&$ tx tnew s\%5Btt news \%5D=181\&cHash=bcb1706a dd.

89. PlasticsEurope - Plastics - the Facts; 2013.

Available:http://www.plasticseurope.org/Do cument/plastics-the-facts2013.aspx?FollD $=2$

90. Datta R, Tsai SP, Bonsignore $\mathrm{P}, \mathrm{Moon} \mathrm{SH}$, Frank JR. Technological and economic potential of poly(lactic acid) and lactic acid derivatives. FEMS Microbiol. Rev. 1995;1999:16(2-3):221-231.

91. Yu Y, Storti G, Morbidelli M. Ring-opening polymerization of I,I-lactide: Kinetic and modeling study. Macromolecules. 2009; 42(21):8187-8197.

92. Ludovic.'

Available:http://www.scconsultants.com/en lludovic-twin-screw-simulationsoftware.htm

93. Available:http://pubs.rsc.org/en/Content/Art icleLanding/2007/GC/b608891k\#!divAbstra $\underline{\mathrm{ct}}$

94. Sinnwell S, Ritter H. Aust. J. Chem. 2007; 60:729.

Available:http://dx.doi.org/10.1071/CH0721 $\underline{9}$

95. Synthesis and recycle of poly(I-lactic acid) using microwave irradiation. Koichi Hirao, Hitomi Ohara, Polymer Reviews. 2011;51(1). 
96. Satya. P. Dubey. Mathematical-modelingfor-continuous-reactive-extrusion-of-polylactic-acid-formation-by-ring-openingpolymerization-considering-metal-organiccatalyst-and-alternative-energies.

International Journal of Chemical, Molecular, Nuclear, Materials and Metallurgical Engineering. 9:2.
97. Dubey $\mathrm{S}$, Abhyankar $\mathrm{H}$, Marchante $\mathrm{V}$, Brighton J, Blackburn K, Temple C, Bergmann B, Trinh G, David C. Modelling and validation of synthesis of poly lactic acid using an alternative energy source through a continuous reactive extrusion process. Polymers. 2016; $8(4): 164$.

() 2016 Dubey et al.; This is an Open Access article distributed under the terms of the Creative Commons Attribution License (http://creativecommons.org/licenses/by/4.0), which permits unrestricted use, distribution, and reproduction in any medium, provided the original work is properly cited.

Peer-review history:

The peer review history for this paper can be accessed here: http://sciencedomain.org/review-history/15723 
2016-08-09

\section{Chronological review of the catalytic progress of polylactic acid formation through ring opening polymerization}

Dubey, Satya P.

SCIENCEDOMAIN International

Dubey, S. P. et al. (2016) Chronological review of the catalytic progress of polylactic acid formation through ring opening polymerization, International Research Journal of Pure and Applied Chemistry, Volume 12, Issue 3 2016, Article number IRJPAC.27469, pp. 1-20 http://dx.doi.org/10.9734/IRJPAC/2016/27469

Downloaded from Cranfield Library Services E-Repository 